\title{
Experimental Teaching Evaluation Based on Multiple Intelligence theory
}

\author{
Wang lixin \\ School of Media and Communications Technology, \\ Liaocheng University \\ Liaocheng Shandong China \\ lxwang@lcu.edu.cn
}

\author{
Fu chonggang \\ School of chemistry and chemical engineering, \\ Liaocheng University \\ Liaocheng Shandong China \\ cgfu@lcu.edu.cn
}

\begin{abstract}
Modern educational technology experiment' is a required course for students of teacher education major to cultivate professional skills. Previously, the evaluation of this course was mainly based on the paper experimental reports and multimedia works submitted by students, this way of summative evaluation focused on the students' language and logical intelligence, cannot reflect the students' other intelligent characteristics. In this paper, based on the multiple intelligences theory, the evaluation principles and a new evaluation method were proposed. The method consists of 5 steps: selecting intelligent type; building a suitable evaluation situation; determining evaluation bodies; setting up evaluation levels and corresponding criteria for every level and generating the evaluation result. This method is comprehensive and exercisable, raised level of experimental teaching and promoted the development of students' multiple intelligences.
\end{abstract}

Keywords-multiple intelligences; experimental teaching; teaching evaluation; evaluation method

\section{INTRODUCTION}

'Modern educational technology experiment' is a required course for students of teacher education major to cultivate professional skills. Previous evaluation of the course was mainly based on paper experimental reports and multimedia works submitted by students, this way of summative evaluation focuses mainly on the students' linguistic and logical intelligence. But we found that students' intelligence shown in the experiment process differ from each other in thousands ways. Some students' hands-on ability is very strong but language expression ability is weak, some students were strong in image thinking ability but weak in logical thinking ability, some students are good at observation and understanding but afraid to communicate with others; In addition, the way of thinking differ greatly due to their different disciplines background. These differences are reflected in the writing of experiment report and submitted multimedia works. Some students well understand the principle and skillful operation of the multimedia equipment, but their experiment reports lack logic and order. So, to judge the students' experimental achievement only from the experiment report is obviously unfair. Furthermore, in spite of positive efforts some students

Experimental technology research fund of Liaocheng university

( LDSY2014062) ; Adult education research found of Liaocheng university (12506KY1511) still cannot make out high-quality multimedia works due to weak academic foundation, if the experimental evaluation take into account only student's multimedia works but without their usual performance, the students' enthusiasm for learning could be hurt seriously. Therefore, a comprehensive, objective and accurate experimental teaching evaluation method is the guarantee of success in experiment teaching. Many people have tried to improve experimental teaching evaluation based on the theory of multiple intelligences, but there is still lack of operatable strategy [1-7]. In this paper, the multiple intelligence theory based evaluation principles were proposed along with an exercisable evaluation method for experiment teaching.

\section{THE THEORY OF MULTIPLE INTELLIGENCES AND ITS PRINCIPAL VIEWS}

Through studies of normal and excellent talent of children, as well as the adult of damaged brain, developmental psychologist Dr. Gardner defined the intelligence of people as the ability to solve a problem or to create products under the specific cultural background or in the society [8]. He thought that there were at least eight kinds of independent and interconnected intelligence, i.e. linguistic intelligence: Sensitivity to sounds, rhythms and meanings of words, and to different uses of language; logical-mathematical intelligence: the capacity to recognize logical or numerical patterns and handle chains of reasoning; spatial intelligence: the ability to perceive the visual-spatial world accurately and act on initial perception; musical intelligence: the ability to perceive, appreciate and produce rhythm, pitch and forms of musical expression; bodily-kinesthetic intelligence: the control of body movements and the capacity to handle objects skilfully; interpersonal intelligence: sensitivity to moods, desires, motivations and feelings of others and the ability to respond appropriately; intrapersonal intelligence: self-knowledge and understanding of own feelings, and ability to access to guide behavior; naturalist intelligence: the ability to recognize and classify flora and fauna. Traditional view of intelligence mainly refers to linguistic intelligence and logical-mathematical intelligence; other intelligences can only be classified as nonintellectual factors and always be despised.

From the point of view of multiple intelligence theory, human intelligence has the following characteristics, (1) 
diversity. Everyone has the eight kinds of intelligence of equal importance. But the traditional intelligence theory judges the degree of intelligence usually from intelligence quotient (IQ) data. The majority of people are excluded from the scope of the wise because their IQ data are not enough. In contrast, multiple intelligences theory emphasizes on the way people are smart. No matter which one of eight kinds of intelligence one has, is outstanding, he is considered a wise man. (2) Situationality. Human intelligence is the ability to solve a problem or to create products in a specific cultural background or society, that is to say, some kinds of intelligence can only be stimulated out in certain circumstances. For example, a skillful, yet timid piano player in a strange environment may not be able to complete originally familiar tunes; a child being berated by his teacher or parents even cannot recite a very simple short poem. In addition, different types of intelligence have different external performance in different situations. For example, a girl will show the attention to detail only when taking part in her adept classroom model activities; yet she will show the impulsiveness in her weaknesses-feeling music activities. (3) Differentiality. There are intelligence differences between people. Each of us has our own unique intelligence ingredients, our own intellectual strengths and weaknesses. Intellectual strength level varies from person to person. We should face up to the intellectual difference between students in the teaching process and create opportunities for all students. Education researchers also have emphasized the need for learning settings to be adaptable and flexible in order for personalized learning to take root [9]. (4) Developmentality. The human intelligence is only a biologically physiological potential, people don't naturally have the abilities to deal with the problem and create products, but the abilities need to be cultivated and developed under a specific social and cultural environment. The purpose of education is to provide the most suitable environment for the students to develop their intelligence.

\section{PRINCIPLE of EXPERIMENTAL TEACHING EVAluAtion BASED ON THE MULTIPLE INTELLIGENCE THEORY}

The multiple intelligence theory not only attaches great importance to the linguistic intelligence and logicalmathematical intelligence, as the traditional intelligence theory does, but also pay attention to other intelligent types known as non-intelligence factors. This theory just coincides with the ideas in the outline of national medium- and long-term education reform and development plan of China. That is to promote organic fusion of moral education, intellectual education, physical education, aesthetic education, improve students' comprehensive quality, make their morality, intelligence and physique full scale development, causes them to become socialist builders and successors. The multiple intelligences theory divides human intelligence into eight kinds, which almost cover all kinds of human intelligence. It provides a theoretical basis and operational feasibility for us to carry out teaching and design the teaching evaluation scheme. From the perspective of the multiple intelligences theory, the establishment of evaluation scheme on the experiment teaching should be based on the following five principles:
A. Authenticity: to provide real situation for the development of intelligence, judge students' ability in real situation

The biggest advantage of experiment teaching is situational. Experiment teaching provides the environment for students to validate the theoretical knowledge leaned from the text book, the opportunity to actually operate experimental equipment and try to solve the actual problem. The role of teaching evaluation is to get the real state in the teaching process, such as the intelligence manifestation of the students in a specific teaching situation, but cannot be disturbed by subjectivism [10]. Only in this way, the evaluation results are helpful to find out the problems existing in the teaching, analyze the cause of the problem and seek the method to solve the problem. Therefore, the reasonable authenticity of the teaching evaluation situation is the premise of correct judgment.

\section{B. Diversity: Multiple intelligence evaluation provides more opportunities for the students to be recognized}

Every student is the combination of multiple intelligence, these intelligences exist independently. Through the training of experiment course, each students gain an improvement in different variety and degree of intelligence in the same experiment project due to their different intelligence structures. Therefore, in the experimental teaching evaluation we should examine the student's performance from point of view of multiple intelligences. For example, student A, who has outstanding spatial intelligence, can successfully achieve connection of devices without difficulty through matching appearance of wire-ends and ports; Student B, who has a strong logical thinking ability, can always connect devices with wires smoothly and correctly according to the logical relationship of signal between the upstream and the downstream devices. Although they (as A and B) could make a different performance in term of time cost and probability of malfunction, all their abilities should be recognized. This is also advocated by the positive outlook on students.

\section{Hierarchicality: to accept the intelligence difference bettewn students,provide development opportunities for all the students}

According to the theory of multiple intelligences, Gardner put forward a three-level intelligence cultivation model. Level one: Gathering information. Students identify and screen information through search, consulting, records or observation to obtain various kinds of useful information. Level two: processing and integration of the existing information. Teachers should guide the students to ponder questions from different angles of view, analyze and evaluate the advantages and disadvantages of many schemes, puts forward the ways to solve the current practical problems, gradually improve the ability to solve problem. Level three: cultivating and improving the ability of innovation. And therefore, the human intelligence is developed progressively, from the first level to the second and final to the third level.

It is indisputable fact that there are individual differences among students' intelligences. Some students can achieve the third level, while others can only reach the first level. Therefore, teaching evaluation should be hierarchical; each student can find his own place in the evaluation level. More 
intelligent students can play exemplary role and the differential evaluation can promote progress of less-intelligent students; On the other hand, all students can benefit from the teaching evaluation.

\section{Multi-subjectivity: to evaluate from the perspective of different subjects, making the evaluation more comprehensive}

The purpose of the experimental teaching evaluation should be to recognize the student's performance, promote the students' reflection. Previous evaluation is given only by the teacher. The summative assessment of students' experiment reports and multimedia works is only made from the perspective of teachers, students become a bystander and passive recipients, evaluation results may be biased. So student's participation in the experimental teaching evaluation is significant and necessary. In this case, Students may pay more attention to their own performance in teaching activities and ability to make works. This self-evaluation can promote students to devote to studying and the development of intrapersonal intelligence. Mutual evaluation among students can promote their communication, understanding, and develop the students' interpersonal intelligence. The Participating of all relevant personnel in the experiment teaching evaluation can make the evaluation more objective, comprehensive and accurate.

\section{E. Priority: Because the teaching goal of every experiment project is different, evaluations should emphasize particularly on some intelligences.}

All kinds of human intelligence have the same importance without differences. The development of the each intelligence has important role in improving the comprehensive ability. But, because of the limits of the teaching-hours, each experiment projects are required to complete within a limited period of time, so teachers can only focus on observation of one or several intelligent performance of the students in the teaching process. It is necessary to determine which intelligent performance needs to pay attention to. This should take several factors into account such as teaching contents and goals, teaching forms, software and hardware environment. There should be obvious priorities and specific focus in the observation on the performance of students during the experimental process. Only in this way can teachers achieve the goal of reasonable teaching evaluation in a limited teaching-hours.

\section{Multiple InTELligence EVAluAtion Method FOR EXPERIMENT TEACHING}

Previously, the evaluation method on modern education technology experiments is through experimental report and multimedia works submitted by students. This is a kind of summative assessment and lack interaction with student's participation in the teaching evaluation process. Additionally, it also did not include other intelligence manifestation of students into the evaluation scope. Multiple intelligence evaluation, which is based on the real situation, can make up for the defect. 'Use of electronic whiteboard software' is an important part of the course of 'the modern education technology experiment'.
Taking this experiment as an example, exercisable, multipleintelligence based evaluation methods were proposed for the experiment teaching. The evaluation method consists of 5 stages: (1) selecting intelligent type to examine; (2) building a suitable evaluation situation; (3) determining evaluation subjects; (4) setting up an evaluation criteria for each level; (5) generating the evaluation result.

\section{A. Selecting intelligent type to examine}

In the experiment of "use of electronic whiteboard software ", the students' spatial intelligence can be examined through switching of different software working mode and recognition of software interface layout, while the use of Tab can examine students' naturalist intelligence. Because of limited number of electronic whiteboard, several students need perform this experiment together as a group; the interaction between them can reflect the students' interpersonal intelligence. Given that linguistic intelligence and logical-mathematic intelligence can be examined in other areas, such as classroom teaching, experiment report and multimedia works, so spatial intelligence, naturalist intelligence and interpersonal intelligence was given priority to examine in this experimental section.

\section{B. Building a suitable evaluation situation}

For the teaching content of 'use of electronic whiteboard software', a suitable situation of teaching and evaluation were built, in which the experimental devices work well and students learn operation of whiteboard software without interference factors such as poor contact, inaccurate whiteboard positioning and so on. So, such an evaluation situation can guarantee the validity of experimental teaching evaluation.

\section{Determining evaluation bodies}

Several students, as a group, perform operation of the software independently; teachers are responsible for solving the problem of students encountered in the operation and observing the student's performance in real time. So teachers are the main evaluation body. The student individuals as one of evaluation body can also make self-evaluation about their own performance and the self-evaluation can improve development of the intrapersonal intelligence. Additionally, Students of the same group can make mutual evaluation after teamwork. This can enhance the development of their interpersonal intelligence.

\section{Setting up evaluation criteria for each level}

There are a large number of students to perform the experiments. On one hand, students' thinking ways, hands-on abilities and disciplines backgrounds differ greatly. Students of science education major are better at the operation of the experimental devices and software than those of humanities and art education major. On other hand, the interface layout of whiteboard software is very complicated and includes many icons, tabs and menus. Therefore the students are divided into two categories. The evaluation criteria were set up according to the majors with higher and lower levels. The ones from science major were assessed at higher level and the others at lower level by respective evaluation criteria. 


\section{E. Generating evaluation results}

In order to improve teaching efficiency, evaluation tables were designed in advanced before class. There are blank cells and filled out cells with pre-written optional assessment comments in the tables. For every intelligence type, each evaluation body gave out their own evaluation result about the students' performance in the form of realistic comment or quantitative marks according to the criteria. These results were written down in the blank cells of the tables or selected from pre-written assessment comments. Other forms of evaluation results, such as video record, conversation record and so on, also provided a reference for generating quantitative marks.

\section{CONCLUSION}

From the analysis of evaluation tables and the final exam score of the course, we find that there are at least three kinds of implications with the multiple intelligence theory based experimental teaching evaluation method.

Firstly, the students' initiatives are grently increased at every stage of the experiments. The reason lies in the introduction of two evaluation sections, i.e. self-evaluation of student individuals and mutual-evaluation among students. Through referring the evaluation criteria, students have recognized their own duty in the process of experiments. The past occurred phenomena of paying man-hour while make no effort, have been avoided effectively. An obvious rise in quality of every experimental stage was achieved such as preview before the experiment, question raising and problem solving during the experiment, report writing after the experiment, etc.

Secondly, the initiative and effectiveness of communication among students have been increased obviously due to the introduction of interpersonal intelligence evaluation. Additionally, this evaluation method also fostered the consciousness and cooperation spirit of teamwork. So as achieve the goal of complementary advantages and win-win cooperation.

Thirdly, by way the comprehensive evaluation, the traditionally called "poor students" received a more objective and fair assessment. It greatly enhanced their self-confidence. As a result, an ideal goal was obtained that making best use of the advantages and trying to make up for shortcomings.

\section{REFERENCES}

[1] J.S. Li. Multiple intelligence evaluation theory and its revelation for the experimental teaching evaluation. Journal of experimental technology and management, 2010 (4) : 146-149

[2] L.X. zhao. University physics experiment teaching under the guidance of the theory of multiple intelligences study. Journal of jilin institute of education, 2012 (11) : 15-16

[3] H.W. Ju, The role of experimental teaching to cultivating seudents' multiple intelligence. China Modern Educational Equipment, 2009(8): 97-98

[4] J.S. Li. Multiple intelligence evaluation theory and its revelation for the experimental teaching evaluation. Journal of experimental technology and management, 2010 (4) : 146-149
[5] M.M. Wu, H.X. Zhang, The theory and practice of performance assessment, Journal of Teaching and Management,2008(5):6-8

[6] Y.D. Feng, Multiple intelligence based online-learning assessment,Modern Distance Education,2007(2): 55-57

[7] D.M. Dai, H.T. Gao, Exploration on the Theory of Multiple Inte lligence in Teaching of Professional Chemical Experiment. Research and Exploration in Laboratory,2007(12):101-102,148

[8] G. Howard, Z.L. Shen. Multiple intelligences. Beijing: xinhua publishing house, 2003:16

[9] The New Media Consortium. The NMC Horizon Report: 2015 Higher Education Edition EB/OL] 2015/4/26

http://www.nmc.org/publication/nmc-horizon-report-2015-highereducation-edition/

[10] M.N. Wu, Instructional design. Beijing: Higher Education Press, 1994:224 